\title{
FATTY ACID COMPOSITION IN BUCKWHEAT (FAGOPYRUM ESCULENTUM M.) FLOURS AND THEIR EXTRUDED PRODUCTS
}

\begin{abstract}
Gita KRUMINA-ZEMTURE, Department of Nutrition, Faculty of Food Technology, Latvia University of Agriculture, 22 Riga Street, Jelgava, Latvia, LV-3002, gita.krumina@1lu.lv (corresponding author)

Ilze BEITANE, Department of Nutrition, Faculty of Food Technology, Faculty of Food Technology, Latvia University of Agriculture, 22 Riga Street, Jelgava, Latvia, LV-3002, ilze.beitane@1lu.lv

Lipids compose a small part of buckwheat seed, but they play an important role in the quality of food. The aim of this study was to evaluate the composition and content of fatty acids in different buckwheat flours (raw, roasted, white, black and germinated) and their extruded products. Fatty acids were quantified by gas chromatography according to the BIOR-T-012-131-2011 method. The prevalence

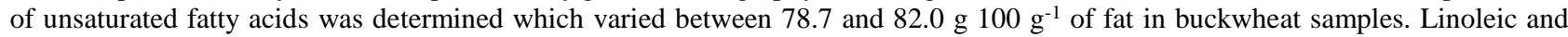
oleic acids were the most abundant unsaturated fatty acids, whereas palmitic acid was the main saturated fatty acid in buckwheat flours and their extruded products. Unsaturated/saturated fatty acid ratio was determined within 3.69 and 4.56, whereas linoleic/ $\alpha$-linolenic acid ratio was between 13.54 and 16.04. No trans-fatty acids in buckwheat flours and their extruded products were observed. The results showed that germination and extrusion of buckwheat flours did not have any effect on the content and composition of fatty acids $(\mathrm{p}>0.05)$.
\end{abstract}

Keywords: buckwheat, extrusion, fatty acids

\section{INTRODUCTION}

In literature buckwheat is characterized as prebiotic and healthy food due to the nutritional composition: resistant starch, amino acids, dietary fibre, phenolic compounds etc. (Préstamo et al., 2003; Qin et al., 2010; Bonafaccia et al., 2003). However, there are no sufficient studies about fatty acid content and composition in buckwheat flour. It is known that the significant part of total fat in buckwheat is composed of unsaturated fatty acids. The results of some studies have been reported about fatty acid composition in buckwheat by pointing to the main fatty acids and unsaturated/saturated fatty acid rate, which was 2.6 and 3.87 in common and 2.94 in Tartary buckwheat (Peng et al., 2017; Alvarez-Jubete et al., 2009; Kim et al. 2004; Bonafaccia et al., 2003).

Germination of pseudo-cereals is a complex method which is used for improving the nutritional value and functionality of the product. Yiming et al. (2015) indicated that germination of buckwheat improved nutritional value of fatty acids. Similar conclusions were reported by Zhang et al. (2015) about the improvement of the total nutritional value in buckwheat seeds after germination.

There has been an interest in extrusion (HTST procedure - high temperature short time) of pseudo-cereals recently. Due to extrusion the structure and digestibility of protein and starch are modified in the product (Anton et al., 2009). Singh et al. (2007) pointed that during extrusion protein denaturation, starch gelatinisation and swelling of fibre were established. Whereas Hagenimana et al. (2006) reported that even after extrusion buckwheat flour contained ungelatinised starch polymers. There is no information about the possible changes of fatty acid content in buckwheat flour during extrusion process.

The aim of this study was to evaluate the composition and content of fatty acids in different buckwheat flours (raw, roasted, white, black and germinated) and their extruded products (made from raw and germinated buckwheat flours).

\section{METHODS}

Buckwheat flours (raw, roasted, white and black) were obtained from the organic farm 'Bebri' (Latvia). Raw buckwheat seeds (organic farm 'Bebri') were used for germination, where seeds were washed with distilled water, soaked for $10 \mathrm{~h}$ at temperature $21 \pm 2{ }^{\circ} \mathrm{C}$, washed, germinated in climate control camera (Memmert, ICH 110) for $24 \mathrm{~h}$ or $48 \mathrm{~h}$ at temperature $25 \pm 2{ }^{\circ} \mathrm{C}$ with $80 \%$ moisture, and dried in dry camera (UF 160) for $4 \mathrm{~h}$ at temperature $40 \pm 2{ }^{\circ} \mathrm{C}$. At the end germinated buckwheat seeds were milled for obtaining flour.

Copyright (C) 2017 The Authors. Published by Aleksandras Stulginskis University. This is an open-access article distributed under the terms of the Creative Commons Attribution License (CC-BY 4.0), which permits unrestricted use, distribution, and reproduction in any medium, provided the original author and source are credited. 
Buckwheat flour (raw and germinated) samples were extruded by food extruder PCE Extrusiometer L-Serie (Göttfert, Germany) with temperature profile: $75 / 90 / 100{ }^{\circ} \mathrm{C}$, the obtained extruded products were dried in convective-rotary oven (Sveba Dahlan, Sweden) for $25 \mathrm{~min}$ at temperature $140 \pm 2{ }^{\circ} \mathrm{C}$ and cooled to room temperature.

The experimental samples were identified with abbreviations (Table 1).

Table 1. Sample abbreviations

\begin{tabular}{|c|l|}
\hline Abbreviation & \multicolumn{1}{|c|}{ Sample } \\
\hline Raw-BF & Raw buckwheat flour \\
\hline Roasted-BF & Roasted buckwheat flour \\
\hline White-BF & White buckwheat flour \\
\hline Dark-BF & Dark buckwheat flour \\
\hline GRBF-24 & Germinated raw buckwheat flour for 24 h \\
\hline GRBF-48 & Germinated raw buckwheat flour for 48 h \\
\hline ERBF & Extruded raw buckwheat flour \\
\hline EGBF-24 & Extruded germinated buckwheat flour (germination for 24 h) \\
\hline EGBF-48 & Extruded germinated buckwheat flour (germination for 48 h) \\
\hline
\end{tabular}

Fatty acids were quantified by gas chromatography according to the BIOR-T-012-131-2011 method in triplicate. The analysis were carried out in the accredited laboratory 'Diagnostic Centre of Institute of Food Safety, Animal Health and Environment'. The data of the research were analysed using the analysis of variance (ANOVA) and $p$-value ( $p<0.05$ ) was used to determine the significant differences.

\section{RESULTS}

In total there were determined 12 unsaturated fatty acids in buckwheat flours and their extruded products: linoleic acid, oleic acid, $\alpha$-linolenic acid, heptadecenoic acid (only in roasted-BF and ERBF), eicosadienoic acid, eicosenoic acid, eicosapentaenoic acid, nervonic acid, palmitoleic acid (not determined in dark-BF), eicosatrienoic acid (only in roastedBF and EGBF-24), docosadienoic acid (only in roasted-BF, GRBF-48 and EGBF-24) and erucic acid (only in white-BF, GRBF-48 and EGBF-24). In Table 2 were presented content of 8 unsaturated and 8 saturated fatty acids which amount

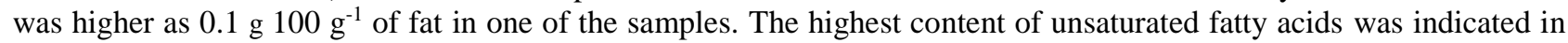
white-BF (82.0 g $100 \mathrm{~g}^{-1}$ of fat), however, there were not observed significant differences among buckwheat flour samples and extruded products ( $\mathrm{p}>0.05)$. In white-BF and EGBF-24 were identified 11 unsaturated fatty acids, in GRBF-48 - 10 , in white-BF and ERBF - 9, in raw-BF, GRBF-24 and EGBF-48 - 8, and in dark-BF - 7 unsaturated fatty acids. The main unsaturated fatty acids were linoleic and oleic acids which represented approximately $70 \%$ of the total fatty acids in buckwheat flours and their extruded products.

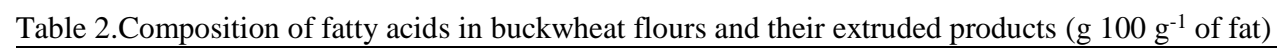

\begin{tabular}{|c|c|c|c|c|c|c|c|c|c|}
\hline & Raw-BF & $\begin{array}{c}\text { Roasted- } \\
\text { BF }\end{array}$ & White-BF & Dark-BF & GRBF-24 & GRBF-48 & ERBF & EGBF-24 & EGBF-48 \\
\hline \multicolumn{10}{|c|}{ Unsaturated fatty acids } \\
\hline $\mathrm{C} 18: 2 \mathrm{n} 6 \mathrm{c}$ & $38.6 \pm 1.9$ & $37.7 \pm 1.8$ & $40.5 \pm 2.0$ & $37.9 \pm 1.9$ & $40.3 \pm 2.0$ & $40.9 \pm 2.0$ & $38.5 \pm 1.9$ & $37.7 \pm 1.9$ & $38.9 \pm 1.9$ \\
\hline $\mathrm{C} 18: 1 \mathrm{n} 9 \mathrm{c}$ & $34.9 \pm 1.7$ & $34.9 \pm 1.7$ & $34.9 \pm 1.7$ & $32.2 \pm 1.6$ & $33.8 \pm 1.7$ & $33.9 \pm 1.7$ & $35.6 \pm 1.8$ & $34.3 \pm 1.7$ & $35.0 \pm 1.8$ \\
\hline C18:3 n3 & $2.5 \pm 0.6$ & $2.4 \pm 0.6$ & $2.6 \pm 0.7$ & $2.8 \pm 0.7$ & $2.8 \pm 0.7$ & $2.8 \pm 0.7$ & $2.4 \pm 0.6$ & $2.5 \pm 0.6$ & $2.5 \pm 0.6$ \\
\hline C20:1 & $3.0 \pm 0.8$ & $3.0 \pm 0.8$ & $3.0 \pm 0.8$ & $2.6 \pm 0.7$ & $2.9 \pm 0.7$ & $2.9 \pm 0.7$ & $2.9 \pm 0.8$ & $2.8 \pm 0.7$ & $2.8 \pm 0.7$ \\
\hline $\mathrm{C} 20: 2$ & 0.1 & 0.1 & $0.2 \pm 0.1$ & $1.0 \pm 0.3$ & $0.2 \pm 0.1$ & 0.1 & 0.1 & $0.2 \pm 0.1$ & $0.2 \pm 0.1$ \\
\hline $\mathrm{C} 20: 5$ & 0.1 & 0.1 & $0.2 \pm 0.1$ & $1.2 \pm 0.3$ & $0.2 \pm 0.1$ & $0.2 \pm 0.1$ & 0.1 & $0.2 \pm 0.1$ & 0.1 \\
\hline C24:1 & $0.2 \pm 0.1$ & $0.2 \pm 0.1$ & $0.3 \pm 0.1$ & $1.0 \pm 0.3$ & $0.2 \pm 0.1$ & $0.2 \pm 0.1$ & $0.2 \pm 0.1$ & $0.3 \pm 0.1$ & $0.3 \pm 0.1$ \\
\hline C16:1 & $0.2 \pm 0.1$ & $0.2 \pm 0.1$ & $0.2 \pm 0.1$ & n.d. & $0.2 \pm 0.1$ & $0.2 \pm 0.1$ & $0.2 \pm 0.1$ & $0.2 \pm 0.1$ & $0.2 \pm 0.1$ \\
\hline Total & 79.6 & 79.0 & 82.0 & 78.7 & 80.6 & 81.4 & 80.1 & 79.5 & 80.0 \\
\hline \multicolumn{10}{|c|}{ Saturated fatty acids } \\
\hline C14:0 & 0.1 & 0.1 & 0.1 & n.d. & 0.1 & 0.1 & $0.2 \pm 0.1$ & $0.2 \pm 0.1$ & $0.2 \pm 0.1$ \\
\hline C15:0 & 0.1 & 0.1 & 0.1 & n.d. & 0.1 & 0.1 & 0.1 & 0.1 & 0.1 \\
\hline C16:0 & $14.3 \pm 1.4$ & $14.7 \pm 1.5$ & $11.9 \pm 1.2$ & $11.3 \pm 1.1$ & $13.6 \pm 1.4$ & $12.5 \pm 1.3$ & $14.1 \pm 1.4$ & $14.3 \pm 1.4$ & $13.6 \pm 1.4$ \\
\hline C18:0 & $1.7 \pm 0.4$ & $1.9 \pm 0.5$ & $1.7 \pm 0.4$ & $2.4 \pm 0.6$ & $1.7 \pm 0.4$ & $1.7 \pm 0.4$ & $1.7 \pm 0.4$ & $1.8 \pm 0.5$ & $1.8 \pm 0.5$ \\
\hline C20:0 & $1.3 \pm 0.3$ & $1.4 \pm 0.4$ & $1.3 \pm 0.3$ & $0.9 \pm 0.2$ & $1.3 \pm 0.3$ & $1.3 \pm 0.3$ & $1.2 \pm 0.3$ & $1.3 \pm 0.3$ & $1.3 \pm 0.3$ \\
\hline $\mathrm{C} 22: 0$ & $1.6 \pm 0.4$ & $1.6 \pm 0.4$ & $1.3 \pm 0.3$ & $2.5 \pm 0.6$ & $1.5 \pm 0.4$ & $1.5 \pm 0.4$ & $1.3 \pm 0.3$ & $1.3 \pm 0.3$ & $1.4 \pm 0.4$ \\
\hline C23:0 & 0.1 & 0.1 & $0.3 \pm 0.1$ & n.d. & 0.1 & 0.1 & $0.2 \pm 0.1$ & $0.2 \pm 0.1$ & $0.2 \pm 0.1$ \\
\hline C24:0 & $0.9 \pm 0.2$ & $0.9 \pm 0.2$ & $1.1 \pm 0.3$ & $1.5 \pm 0.4$ & $0.9 \pm 0.2$ & $0.9 \pm 0.2$ & $0.8 \pm 0.2$ & $0.9 \pm 0.2$ & $0.9 \pm 0.2$ \\
\hline Total & 20.4 & 21.0 & 18.0 & 21.3 & 19.4 & 18.2 & 19.9 & 20.5 & 20.0 \\
\hline
\end{tabular}

n.d. - not determined

The total of 14 saturated fatty acids was determined in experimental samples: myristic acid (not determined in dark-BF), pentadecyclic acid (not determined in dark-BF), palmitic acid, stearic acid, arachidic acid, behenic acid, tricosylic acid (not determined in dark-BF), lignoceric acid, heneicosanoic acid (only in raw-BF, roasted-BF and GRBF24), heptadecanoic acid (only in raw-BF and roasted-BF), caprylic acid (only in dark-BF, ERBF, EGBF-24 and EGBF- 
48), capric acid (only in dark-BF and EGBF-48), caproic acid (only in white-BF, ERBF, EGBF-24 and EGBF-48) and lauric acid (only in ERBF, EGBF-24 and EGBF-48). The highest content of saturated fatty acids was observed in darkBF but the differences among samples were insignificant ( $\mathrm{p}>0.05) .12$ saturated fatty acids were identified in EGBF-48, 11 - in ERBF and EGBF-24, 10 - in raw-BF and roasted-BF, 9 - in white-BF and GRBF-24, 8 - in GRBF-48, and 7 saturated fatty acids - in dark-BF. The main saturated fatty acid in experimental samples was palmitic acid.

Unsaturated/saturated fatty acid ratio (Table 3) is used for evaluation of fatty acid composition in buckwheat flours and their extruded products. The highest ratio of unsaturated/saturated fatty acids among experimental samples was in white-BF whereas the lowest - in dark-BF.

Table 3. Ratios of unsaturated/saturated fatty acids and linoleic/ $\alpha$-linolenic acids in buckwheat flours and their extruded products

\begin{tabular}{|l|c|c|}
\hline \multicolumn{1}{|c|}{ Samples } & Unsaturated/saturated fatty acid ratio & Linoleic/ $\alpha$-linolenic acid ratio \\
\hline Raw-BF & 3.90 & 15.44 \\
\hline Roasted-BF & 3.76 & 15.71 \\
\hline White-BF & 4.56 & 15.58 \\
\hline Dark-BF & 3.69 & 13.54 \\
\hline GRBF-24 & 4.15 & 14.39 \\
\hline GRBF-48 & 4.47 & 14.61 \\
\hline ERBF & 4.03 & 16.04 \\
\hline EGBF-24 & 3.88 & 15.08 \\
\hline EGBF-48 & 4.00 & 15.56 \\
\hline
\end{tabular}

When analysing linoleic/ $\alpha$-linolenic acid ratio, the best result in this research was defined by the lowest ratio calculated in dark-BF, whereas ERBF sample had the highest ratio.

\section{CONCLUSIONS AND DISCUSSION}

Different factors like cultivars, growth location, seeding time and processing can affect the fatty acid content and composition of buckwheat flour. However, results of this research about unsaturated fatty acids in buckwheat flours were close to data mentioned in literature. Bonafaccia et al. (2003) indicated that unsaturated fatty acids prevailed over saturated

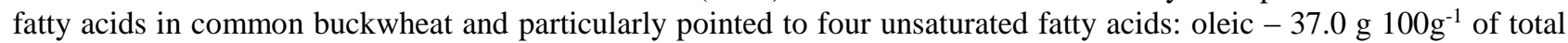

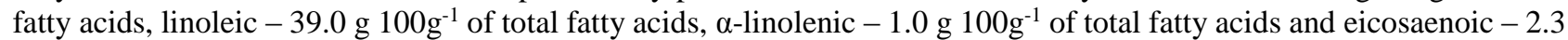
$\mathrm{g} 100 \mathrm{~g}^{-1}$ of total fatty acids, whereas Peng et al. (2017) and Alvarez-Jubete et al. (2009) determined similar composition of fatty acids in buckwheat seeds but with lower content of oleic and linoleic acid and higher content of $\alpha$-linolenic acid. The data of current research confirmed the conclusions of literature about content of the main unsaturated fatty acids in buckwheat flour; however, in small amount it was possible to determine other unsaturated fatty acids like heptadecenoic, eicosadienoic, eicosapentaenoic, nervonic, palmitoleic, eicosatrienoic, docosadienoic and erucic acid.

Evaluating germination effect on unsaturated fatty acid composition and content in buckwheat flour, there were not established any significant changes $(p>0.05)$. Results did not confirm the conclusions in literature. Yiming et al. (2015) reported that the content of linoleic acid in buckwheat seeds decreased during germination. Current research showed an increase of linoleic acid and total unsaturated fatty acid content after germination in raw buckwheat flour though there were not determined significant differences between raw-BF and germinated buckwheat flour samples (GRBF-24 and GRBF-48) (p>0.05).

Extrusion (at temperature till $100{ }^{\circ} \mathrm{C}$ ) and drying in convective-rotary oven (at temperature till $140{ }^{\circ} \mathrm{C}$ ) for obtaining extruded buckwheat products did not make any significant changes in unsaturated fatty acid content and composition in comparison with raw-BF or GRBF-24 and GRBF-48. Therefore it could be concluded that the technological processes like germination and extrusion did not have any significant effect on the content and composition of unsaturated fatty acid content in buckwheat flours and their extruded products $(p>0.05)$. Furthermore no trans-fatty acids in buckwheat flours and their extruded products were observed. Alvarez-Jubete et al. (2009) reported that total C18 trans-fatty acids were not determined in buckwheat seeds, too.

Analysing the results of saturated fatty acid content and composition, the most different buckwheat flour sample was dark-BF, though the observed differences were not significant. In dark-BF only 7 saturated fatty acids were identified besides it contained the lowest amount of palmitic and arachidonic acid and the highest amount of stearic, behenic and lignoceric acid among buckwheat flours and their extruded products. The same conclusions were reported by Peng et al. (2017) that there were no significant differences between black and brown Tartary buckwheat. Data of current research and literature were similar about palmitic acid content in buckwheat which made an important part (53-70\%) of total saturated fatty acid content in buckwheat flours (Bonafaccia et al., 2003; Alvarez-Jubete et al., 2009; Peng et al., 2017). The other saturated fatty acids in buckwheat seeds were stearic, arachidonic and behenic acid mentioned in literature by Bonafaccia et al. (2003), myristic, stearic and arachidonic acid by Peng et al. (2017) and stearic, arachidonic, behenic and lignoceric acid by Alvarez-Jubete et al. (2009) and specified amounts of them were close to current research data. The

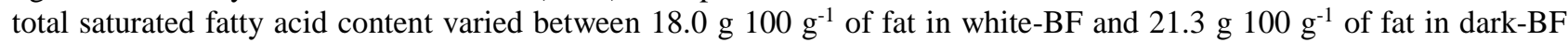

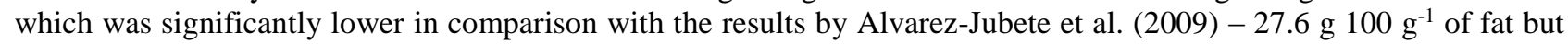

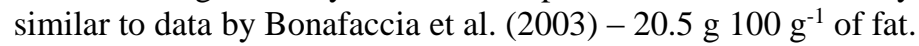


The research data by Yiming et al. (2015) showed that the content of saturated fatty acids like palmitic, stearic and arachidic acid increased during germination that was not confirmed during current research. There were not observed any significant changes in content of saturated fatty acids between raw-BF and germinated buckwheat flours (GRBF-24 and GRBF-48).

Saturated fatty acid content and composition of extruded buckwheat products (ERBF, EGBF-24 and EGBF-48) did not differ from raw and germinated buckwheat flour samples. That means that neither germination nor extrusion had any effect on content and composition of saturated fatty acids in buckwheat flours and their extruded products.

Unsaturated/saturated fatty acid ratio of current research ranged between 3.69 and 4.56 which was similar to data reported by Bonafaccia et al. (2003) - 3.87, but higher in comparison with the data by Alvarez-Jubete et al. (2009) - 2.6. There was observed an increase of unsaturated/saturated fatty acid ratio in raw buckwheat flour during germination from 3.90 in raw-BF to 4.15 in GRBF-24 or 4.47 in GRBF-48, but extrusion caused the decrease of unsaturated/saturated fatty acid ratio in germinated buckwheat flours.

Linoleic/ $\alpha$-linolenic acid ratio of buckwheat flours and their extruded products varied between 13.54 and 16.04. Dark-BF showed the best ratio among experimental samples and was lower than linoleic/ $\alpha$-linolenic acid ratio mentioned in literature about buckwheat seeds - 15.6 (Alvarez-Jubete et al., 2009). Linoleic/ $\alpha$-linolenic acid ratio changes can affect lipid metabolism in human body and it is independent on the intake changes of linoleic and $\alpha$-linolenic acid in nutrition (Goyens et al., 2005). Research by Makrides et al. (2000) showed that the lowering of linoleic/ $\alpha$-linolenic acid ratio in formula for infants provided a modest increase in plasma of DHA. It is known that both polyunsaturated fatty acids are important nutrients in human diet because a human body cannot produce them.

In conclusion, the current research indicated that germination and extrusion of buckwheat flours did not have any significant effect on the content and composition of fatty acids $(\mathrm{p}>0.05)$.

\section{Acknowledgement.}

This research was supported by National Research Programme AgroBioRes (2014-2017) and the project "Strengthening Research Capacity in the Latvia University of Agriculture".

\section{REFERENCES}

1. Alvarez-Jubete, L., Arendt, E.K., Gallagher, E. 2009. Nutritive value and chemical composition of pseudocereals as gluten-free ingredients. International Journal of Food Science and Nutrition, Vol. 60, pp. $240-257$. ttps://doi.org/10.1080/09637480902950597

2. Anton, A.A., Fulcher, R.G., Arntfield, S.D. 2009. Physical and nutritional impact of fortification of corn-starch based extruded snacks with common bean (Phaseolus vulgaris L.) flour: effects of bean addition and extrusion cooking. Food Chemistry, Vol. 113, pp.989-996. https://doi.org/10.1016/j.foodchem.2008.08.050

3. Bonafaccia, G., Marocchini, M., Kreft, I. 2003. Composition and technological properties of the flour and bran from common and tartary buckwheat. Food Chemistry, Vol. 80, pp.9-15. https://doi.org/10.1016/S0308-8146(02)00228-5

4. Goyens, P.L.L., Mensink, R.P. 2005. The dietary $\alpha$-linolenic acid to linoleic acid ratio does not affect the serum lipoprotein profile in humans. The Journal of Nutrition, Vol. 135, pp.2799-2804.

5. Hagenimana, A., Ding, X., Fang, T. 2006. Evaluation of rice flour modified by extrusion cooking. Journal of Cereal Science, Vol. 43, pp.38-46. https://doi.org/10.1016/j.jcs.2005.09.003

6. Kim, S.L., Kim, S.K., Park, Ch.H. 2004. Introduction and nutritional evaluation of buckwheat sprouts as a new vegetable. Food Research International 37, pp.319-327. https://doi.org/10.1016/j.foodres.2003.12.008

7. Makrides, M., Neumann, M.A., Jeffrey, B., Lien, E.L., Gibson, R.A. 2000. A randomized trial of different ratios of linoleic to $\alpha$ linolenic acid in thediet of term infants: effects on visual function and growth. The American Journal of Clinical Nutrition, Vol. 71, pp.120-129.

8. Peng, L.X., Zou, L., Tan, M.L., Deng, Y.Y., Yan, J., Yan, Z.Y., Zhao, G. 2017. Free amino acids, fatty acids, and phenolic compounds in tartary buckwheat of different hull colour. Czech Journal of Food Sciences, Vol. 35, pp.214-222. https://doi.org/10.17221/185/2016-CJFS

9. Préstamo, G., Pedrazuela, A., Peňas, E., Lasunción, M.A., Arroyo, G. 2003. Role of buckwheat diet on rats as prebiotic and healthy food. Nutrition Research, Vol. 23, pp.803-814. https://doi.org/10.1016/S0271-5317(03)00074-5

10. Qin, P., Qiang, W., Shan, F., Hou, Z., Ren, G. 2010. Nutritional composition and flavonoids content of flour from different buckwheat cultivars. International Journal of Food Science \& Technology, Vol. 45, pp.951-958. https://doi.org/10.1111/j.13652621.2010.02231.x

11. Singh, B., Sekhon, K.S., Singh, N. 2007. Effects of moisture, temperature and level of pea grits on extrusion behaviour and product characteristics of rice. Food Chemistry, Vol. 100, pp.198-202. https://doi.org/10.1016/j.foodchem.2005.09.042

12. Yiming, Z., Hong, W., Linlin, C., Xiaoli, Z., Wen, T., Xinli, S. 2015. Evolution of nutrient ingredients in tartary buckwheat seeds during germination. Food Chemistry, Vol. 186, pp.244-248. https://doi.org/10.1016/j.foodchem.2015.03.115

13. Zhang, G., Xu, Z., Gao, Y., Huang, X., Zou, Y., Yang, T. 2015. Effects of germination on the nutritional properties, phenolic profiles, and antioxidant activities of buckwheat. Journal of Food Science, Vol. 80, Nr.5. pp.H1111-H1119. $\underline{\text { https://doi.org/10.1111/1750-3841.12830 }}$ 